\title{
Modelagem de propagação das ondas elásticas em meios porosos 1D: modelos de Biot vs. Biot-JKD
}

Oliveira, I. B.*; Azeredo, M. M.; Priimenko, V. I., LENEP-UENF

Copyright 2018, SBGf - Sociedade Brasileira de Geofísica

Este texto foi preparado para a apresentação no VIII Simpósio Brasileiro de Geofísica, Salinópolis, 18 a 20 de setembro de 2018. Seu conteúdo foi revisado pelo Comitê Técnico do VIII SimBGf, mas não necessariamente representa a opinião da SBGf ou de seus associados. É proibida a reprodução total ou parcial deste material para propósitos comerciais sem prévia autorização da SBGf.

\begin{abstract}
In this work, it was analyzed the process of propagation of elastic waves in one-dimensional piecewise constant porous media. The general task was to simulate the poroelastic response and to perform a numericalanalytical analysis of the effect of changing the physical parameters of the medium on the solution of the problem. The process of wave propagation is described by the Biot (low-frequency approximation) and Biot-JKD (highfrequency approximation) equations. The Ursin formalism was used to construct the corresponding solutions. Numerical experiments confirm the effectiveness of the proposed algorithm in identifying the main wave elements in both low-frequency and high-frequency regimes in reservoir and laboratory scales, respectively.
\end{abstract}

\section{Introdução}

A teoria da poroelasticidade descreve a propagação de ondas em um sólido elástico poroso que contém um fluido viscoso, sendo de grande interesse em diversos segmentos da engenharia de petróleo, como por exemplo, na exploração e caracterização de reservatórios de óleo e gás, detecção de hidratos, monitoramento sísmico de armazenamento de $\mathrm{CO}_{2}$ e hidrogeologia.

Além da indústria de petróleo, a teoria da poroelasticidade possui aplicações em outras áreas do conhecimento humano, pode-se citar: a vibroacústica, na qual materiais porosos são utilizados devido suas propriedades de absorção e amortecimento do som; a bioengenharia, na modelagem de estruturas ósseas, etc.

Biot dividiu seu estudo da propagação das ondas elásticas em dois casos: baixas frequências (Biot, 1956a) e altas frequências (Biot, 1956b). A teoria da poroelasticidade assume que os efeitos anelásticos surgem a partir de uma interação viscosa entre o fluido e o sólido e prevê duas ondas compressionais e uma cisalhante. A onda compressional rápida corresponde ao movimento no qual os deslocamentos das fases sólida e fluida estão em fase, enquanto que para a onda compressional lenta, os movimentos são defasados.

Para baixas frequências, o meio não suporta a onda lenta, já que os efeitos da viscosidade do fluido dominam os efeitos inerciais. Para altas frequências, os efeitos inerciais são predominantes e o modo lento é ativado, consequentemente, a amplitude do campo de onda é atenuada devido às perdas de energia em presença de fluido viscoso. Estas características do processo apresentam dificuldades na modelagem da propagação das ondas em meios poroelásticos.

Johnson et al. (1987) publicaram uma expressão geral para a dissipação de energia no caso de poros aleatórios, conduzindo ao modelo de Biot-JKD. Este modelo é determinado pela permeabilidade dinâmica, a qual resulta do aparecimento da camada viscosa nas paredes dos poros.

A metodologia utilizada se baseia na teoria da poroelasticidade e no formalismo de Ursin (1983). Os resultados apresentados neste resumo expandido são decorrentes da dissertação de mestrado do Oliveira (2018).

A originalidade deste trabalho está associada ao desenvolvimento de um método/algoritmo para construção da solução de problemas diretos para os sistemas das equações de Biot e Biot-JKD e criação de um código computacional para simulação numérica da propagação das ondas elásticas em meios porosos saturados, e posterior avaliação/comparação das respostas obtidas para os domínios de frequências baixas e altas.

\section{Teoria e Método}

Para o caso unidimensional (1D), quando os parâmetros dependem somente de uma variável espacial $z$ profundidade, os sistemas das equações de Biot e BiotJKD podem ser formulados da seguinte maneira:

$$
\begin{aligned}
& \rho \partial_{t} v+\rho_{f} \partial_{t} q=\partial_{z} \sigma+f \\
& \rho_{f} \partial_{t} v+F_{e} \rho_{f} \partial_{t} q=-\partial_{z} p_{f}-\mathcal{L}(t) * q+g \\
& \partial_{t} \sigma=(\lambda+2 G) \partial_{z} v+C M \partial_{z} q \\
& -\partial_{t} p_{f}=C M \partial_{z} v+M \partial_{z} q
\end{aligned}
$$

onde * é o operador de convolução e o termo $\mathcal{L}(t)$, no domínio da frequência temporal $\omega$, é representado por:

$$
\mathcal{L}(\omega)=\frac{\eta}{k} \begin{cases}1 & \text { Biot } \\ \sqrt{1+\frac{i \omega}{\Omega}}, & \text { Biot }-J K D\end{cases}
$$

sendo que $\rho$ é a massa específica total do meio poroso, $v$ é a velocidade de deslocamento absoluto da fase sólida, $\rho_{f}$ é a massa específica do fluido, $q$ é a velocidade 
relativa de filtração de Darcy, $\sigma$ é a tensão, $f$ é a força externa na fase sólida, $F_{e}$ é o fator elétrico da formação, representado pela razão entre a tortuosidade (a) e a porosidade $(\phi)$ do meio, $p_{f}$ é a pressão efetiva, $g$ é a força externa na fase líquida, $\lambda$ é o parâmetro de Lamé, $G$ é o módulo de cisalhamento, $C$ e $M$ são os módulos de Biot, $\eta$ é a viscosidade do fluido, $k$ é a permeabilidade absoluta do meio, $i^{2}=-1$ e $\Omega$ é a frequência de relaxação.

A Equação (1) representa a conservação total do momento linear, (2) é a lei de Darcy generalizada e as Equações (3) e (4) são as leis constitutivas de tensão e deformação do meio poroso isotrópico, respectivamente.

As condições de fronteira para o problema são (Carcione, 2007): na interface de descontinuidade entre duas camadas as variáveis $v, q, \sigma$ e $p_{f}$ são contínuas, além disso, na superfície livre a tensão e a pressão efetiva desaparecem. Como dado inicial considerou-se que até o tempo $t=0$ as variáveis do problema são nulas.

Segundo Blanc (2013), inserindo-se um modo $e^{i(\omega t-\kappa z)}$ nos sistemas das equações de Biot e Biot-JKD (1)-(4), com $f=g \equiv 0$, deriva-se a relação de dispersão entre a frequência $\omega$ e o número de onda $\kappa$.

As Figuras 1-4 mostram as curvas de dispersão e atenuação correspondentes aos modelos de Biot e BiotJKD para quatro experimentos distintos: meio poroso $100 \%$ saturado com (1) água; (2) óleo leve $36^{\circ} \mathrm{API}$; (3) óleo médio $24,7^{\circ} \mathrm{API}$ e (4) óleo pesado $14,8^{\circ} \mathrm{API}$. As propriedades físicas do meio poroso e dos fluidos foram retiradas dos trabalhos de Blanc (2013) e Al-Besharah et al. (1987) e estão presentes na Tabela 1.

Tabela1: Propriedades físicas do meio poroso e dos fluidos utilizados na análise de dispersão e atenuação

\begin{tabular}{cccc}
\hline Propriedade & Símbolo & Unidade & Valor \\
\hline Massa específica da água & $\rho_{a}$ & $\mathrm{~kg} / \mathrm{m}^{3}$ & 1000 \\
Massa específica do óleo leve & $\rho_{o l}$ & $\mathrm{~kg} / \mathrm{m}^{3}$ & 844,8 \\
Massa específica do óleo médio & $\rho_{o m}$ & $\mathrm{~kg} / \mathrm{m}^{3}$ & 905,9 \\
Massa específica do óleo pesado & $\rho_{o p}$ & $\mathrm{~kg} / \mathrm{m}^{3}$ & 967,2 \\
Viscosidade da água & $\eta_{a}$ & $P a . s$ & $10^{-3}$ \\
Viscosidade do óleo leve & $\eta_{o l}$ & Pa.s & $8,03 \times 10^{-3}$ \\
Viscosidade do óleo médio & $\eta_{\text {om }}$ & Pa.s & $73,79 \times 10^{-3}$ \\
Viscosidade do óleo pesado & $\eta_{o p}$ & Pa.s & $853,78 \times 10^{-3}$ \\
Massa específica da parte sólida & $\rho_{s}$ & $\mathrm{~kg} / \mathrm{m}^{3}$ & 2644 \\
Módulo de cisalhamento & $G$ & $P a$ & $7,04 \times 10^{9}$ \\
Porosidade & $\phi$ & Adimensional & 0,2 \\
Tortuosidade & $a$ & Adimensional & 2,4 \\
Permeabilidade & $k$ & $\mathrm{~m}^{2}$ & $3,6 \times 10^{-13}$ \\
Parâmetro de Lamé & $\lambda$ & Pa & $1,06 \times 10^{10}$ \\
Módulo de Biot & $M$ & $P a$ & $9,7 \times 10^{9}$ \\
Módulo de Biot & $C$ & Adimensional & 0,72 \\
Comprimento viscoso característico & $v$ & $m$ & $5,88 \times 10^{-6}$ \\
\hline
\end{tabular}

As retas verticais tracejadas presentes nas Figuras 1-4 representam a fronteira entre o domínio das baixas e o das altas frequências, determinada quando os esforços viscosos e os inerciais são similares, sendo definida como frequência crítica (Blanc, 2013):

$$
f_{c}=\frac{\eta \phi}{2 \pi a k \rho_{f}}
$$

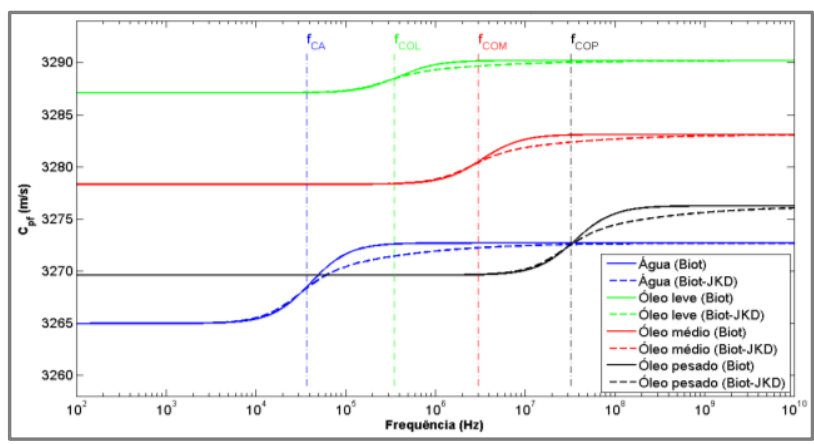

Figura 1: Velocidade de fase da onda rápida

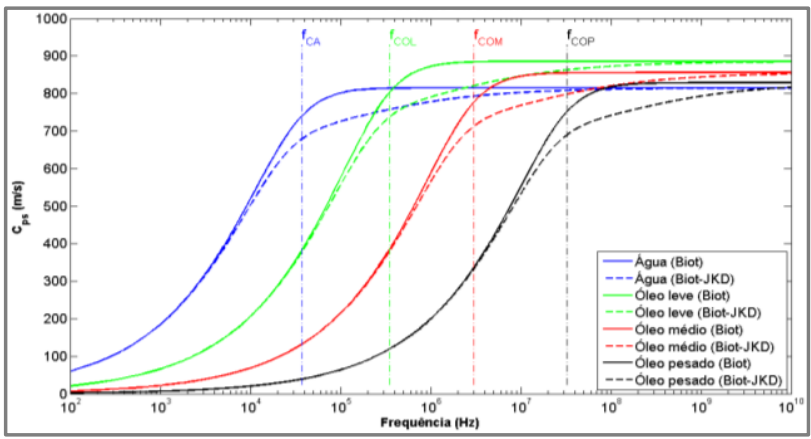

Figura 2: Velocidade de fase da onda lenta

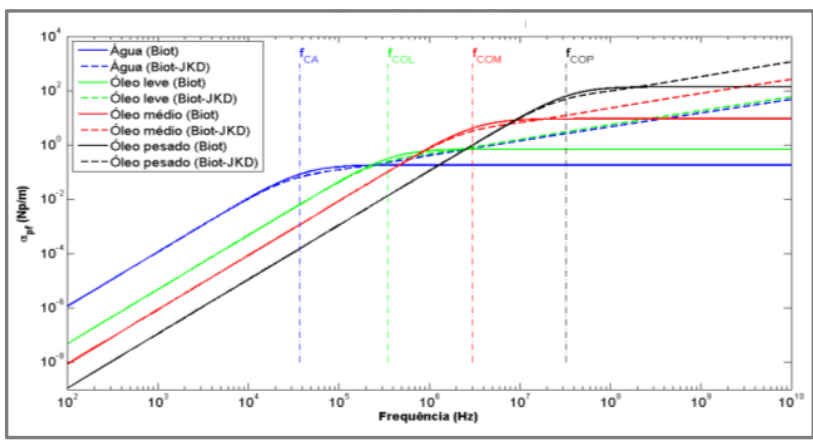

Figura 3: Atenuação da onda rápida

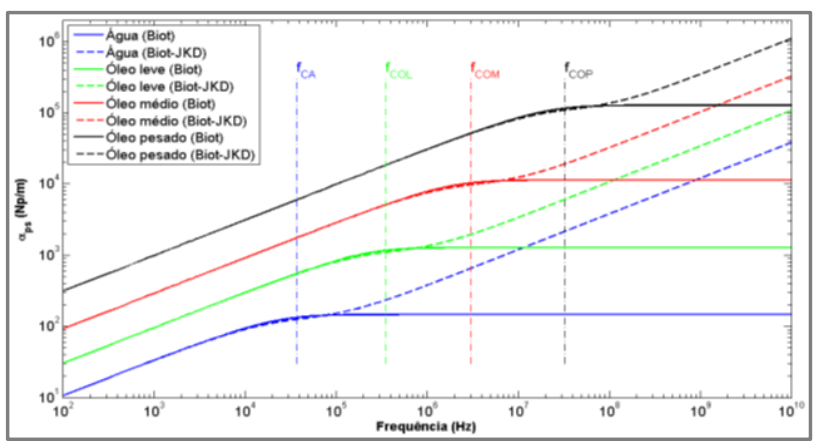

Figura 4: Atenuação da onda lenta 
Baseando-se no formalismo de Ursin (1983), aplicou-se a transformada de Fourier nos sistemas das equações de Biot e Biot-JKD (1)-(4), obtendo assim as equações no domínio da frequência temporal $\omega$. Em seguida, tais equações foram escritas na forma matricial e a solução decomposta em duas partes: ondas ascendentes e descendentes.

Dessa forma, respeitando-se as condições de salto nas fronteiras entre as camadas, determinaram-se, por recursão (Azeredo, 2013), todas as matrizes de reflexão e transmissão nas interfaces de descontinuidade entre os meios porosos.

Finalmente, para encontrar a solução no domínio do tempo aplicou-se a transformada inversa de Fourier na solução encontrada previamente no domínio da frequência.

\section{Resultados}

Para realizar as simulações da propagação das ondas elásticas utilizou-se uma fonte (Figura 5 ), representada por uma função composta por senoides truncadas (Blanc, 2013), definida pela seguinte fórmula:

$$
\begin{aligned}
H(t)=\sin \left(\omega_{d} t\right)- & \frac{21}{32} \sin \left(2 \omega_{d} t\right)+\frac{63}{768} \sin \left(4 \omega_{d} t\right) \\
& -\frac{1}{512} \sin \left(8 \omega_{d} t\right)
\end{aligned}
$$

se $t \in\left(0, f_{d}^{-1}\right)$ e $H(t)=0$ se $t \notin\left(0, f_{d}^{-1}\right)$, onde $f_{d}$ é a frequência dominante da fonte e $\omega_{d}=2 \pi f_{d}$.

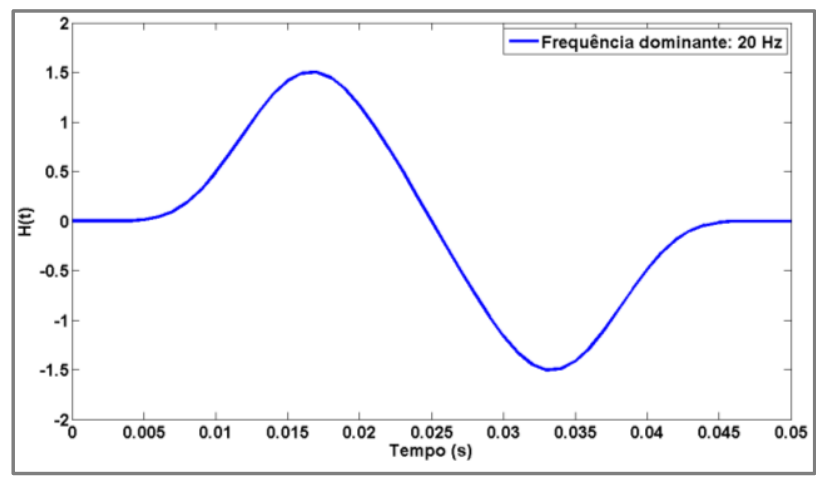

Figura 5: Função da fonte no domínio do tempo com frequência dominante de $20 \mathrm{~Hz}$

Considerou-se uma análise unidimensional de modelos geológicos horizontalmente estratificados, compostos por três camadas homogêneas $e$ isotrópicas. As propriedades físicas de cada camada estão elencadas na Tabela 2.

Os resultados das simulações são apresentados separadamente em relação ao domínio de frequência que pertencem: baixas frequências (escala de reservatório) e altas frequências (escala laboratorial).
Tabela2: Propriedades físicas do meio poroelástico utilizado nas simulações

\begin{tabular}{ccccc}
\hline Propriedade & Símbolo & Unidade & Camadas 1 e 3 & Camada 2 \\
\hline Massa específica do fluido & $\rho_{f}$ & $\mathrm{~kg} / \mathrm{m}^{3}$ & 1040 & 1000 \\
Viscosidade do fluido & $\eta$ & $P a . s$ & $10^{-3}$ & $10^{-3}$ \\
Massa esp. da parte sólida & $\rho_{s}$ & $\mathrm{~kg} / \mathrm{m}^{3}$ & 2650 & 2644 \\
Módulo de cisalhamento & $G$ & $P a$ & $1,85 \times 10^{9}$ & $7,04 \times 10^{9}$ \\
Porosidade & $\phi$ & - & 0,3 & 0,2 \\
Tortuosidade & $a$ & - & 2 & 2,4 \\
Permeabilidade & $k$ & $\mathrm{~m}^{2}$ & $1 \times 10^{-12}$ & $3,6 \times 10^{-13}$ \\
Parâmetro de Lamé & $\lambda$ & $P a$ & $8,4 \times 10^{9}$ & $1,06 \times 10^{10}$ \\
Módulo de Biot & $M$ & $P a$ & $7,05 \times 10^{9}$ & $9,7 \times 10^{9}$ \\
Módulo de Biot & $C$ & - & 0,88 & 0,72 \\
Comp. viscoso característico & $v$ & $m$ & $7,3 \times 10^{-6}$ & $5,88 \times 10^{-6}$ \\
\hline
\end{tabular}

Para o domínio das baixas frequências utilizou-se uma fonte com frequência dominante de $20 \mathrm{~Hz}$. Considerou-se que tanto a fonte quanto o receptor estão localizados na superfície livre, conforme ilustra a Figura 6.

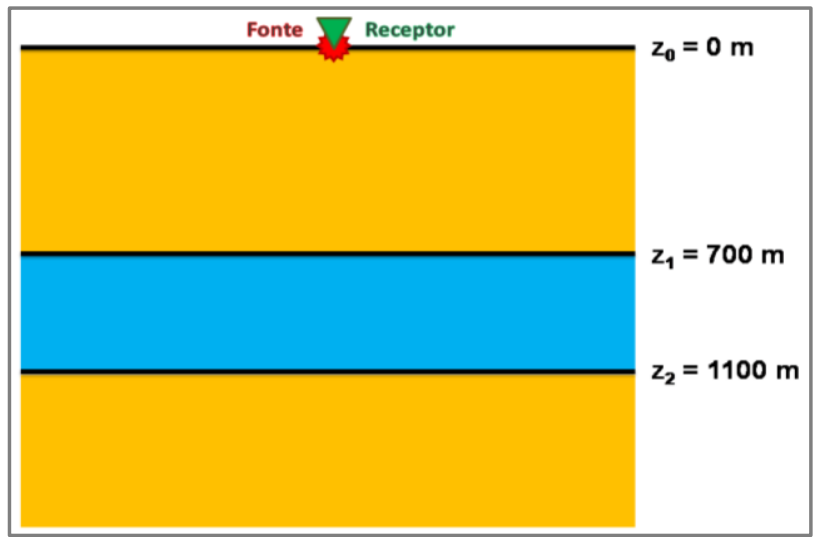

Figura 6: Modelo geológico e arranjo fonte-receptor utilizados para simulação do caso de baixas frequências

A Figura 7 exibe o resultado obtido nesta simulação, onde se plotou a velocidade de deslocamento absoluto da fase sólida tanto para o modelo de Biot (curva azul), quanto para o modelo de Biot-JKD (curva vermelha). As setas numeradas indicam os tempos de chegada dos eventos detectados na simulação. Como visto na Introdução, para baixas frequências o meio não suporta a onda lenta, que se torna difusiva. Além disso, como se realizou uma análise unidimensional, não há a presença da onda cisalhante, dessa forma, todos os eventos observados são referentes à propagação da onda compressional rápida no meio poroelástico. A seta 1 é referente à onda refletida na primeira interface, a numeração 2 indica a onda refletida na segunda interface, já as setas 3 e 4 são referentes às múltiplas internas.

A Figura 8 apresenta o mesmo resultado da Figura 7, porém com um zoom no eixo das ordenadas para melhor visualização dos eventos que possuem menores amplitudes. 


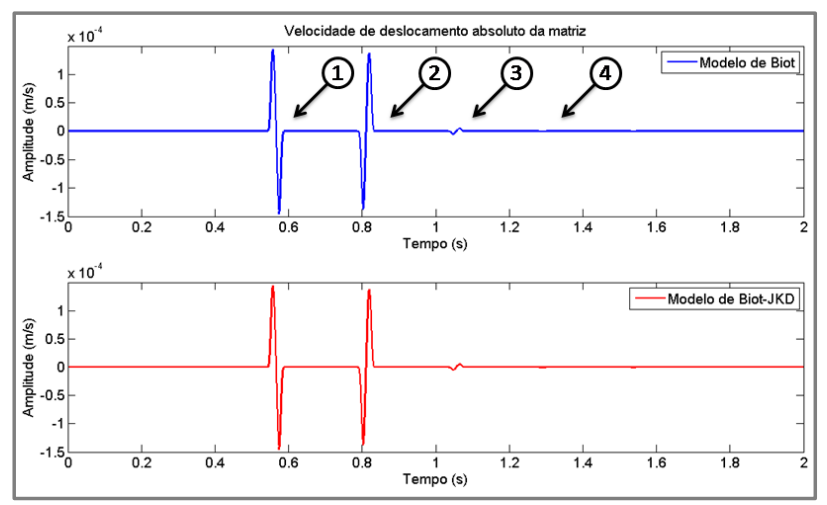

Figura 7: Velocidade de deslocamento absoluto da fase sólida para o caso simulado de baixas frequências

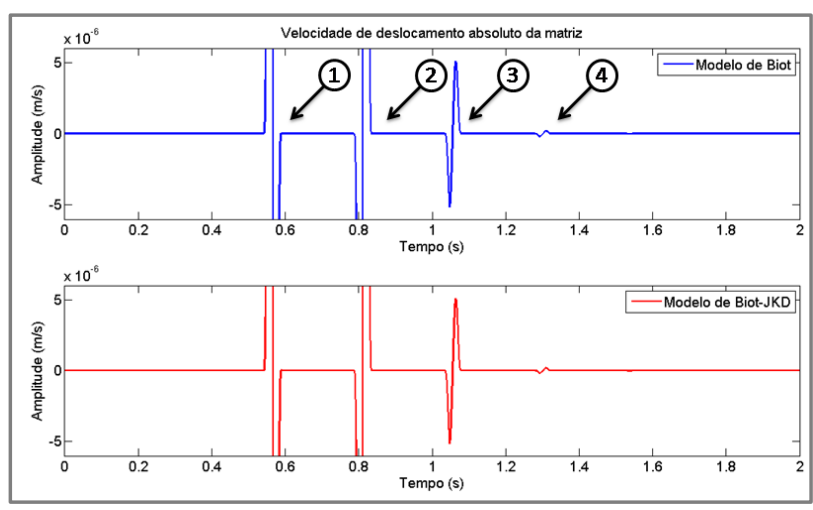

Figura 8: Zoom da velocidade de deslocamento absoluto da fase sólida para o caso simulado de baixas frequências

Já para o domínio das altas frequências utilizou-se uma fonte com frequência dominante de $200 \mathrm{kHz}$. E, da mesma forma, tanto a fonte quanto o receptor estão localizados na superfície livre, veja a Figura 9.

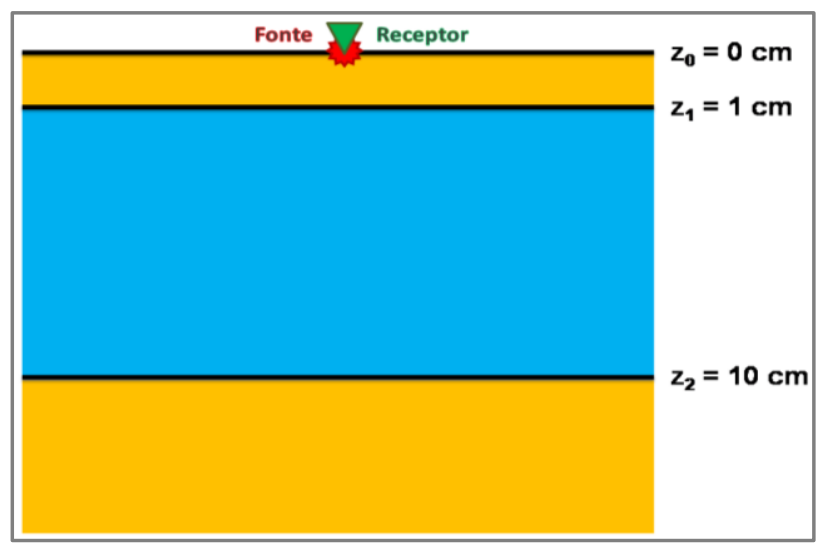

Figura 9: Modelo geológico e arranjo fonte-receptor utilizados para simulação do caso de altas frequências
Como abordado na Introdução, para altas frequências, além da presença da onda rápida pode-se observar a onda lenta que se propaga no meio poroelástico (Figuras 10 e 11).Outro fenômeno visualizado nesta simulação foi a presença da onda compressional convertida rápidalenta e também lenta-rápida, onde a onda elástica ao se propagar converte o seu modo de propagação ao refratar ou refletir em uma interface de descontinuidade entre dois meios poroelásticos distintos, como observado por Bouzidi (2013).

As setas numeradas presentes nas Figuras 10 e 11 apontam os tempos de chegada dos eventos determinados pela simulação. A numeração 1 é referente à onda rápida refletida na primeira interface, a seta número 2 indica a onda convertida rápida-lenta ou lentarápida, haja vista que ambas possuem o mesmo tempo de trânsito neste caso, já a terceira seta assinala a onda lenta refletida na primeira interface, a onda rápida refletida na segunda interface é apontada pela seta número 4, a quinta numeração indica a onda lenta que iniciou sua propagação a partir da fonte, porém foi convertida para onda rápida ao refratar na primeira interface e então refletir na segunda interface e voltar à superfície, sendo assim detectada pelo receptor, e a numeração 6 se refere à múltipla interna da onda rápida.

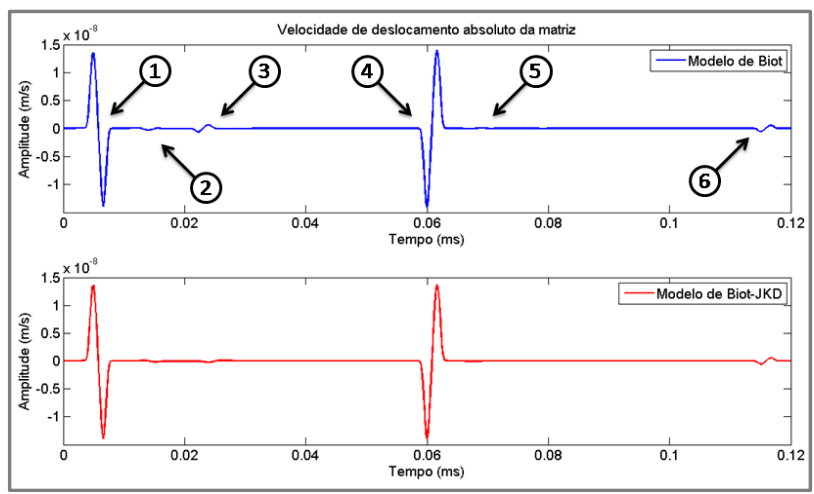

Figura 10: Velocidade de deslocamento absoluto da fase sólida para o caso simulado de altas frequências

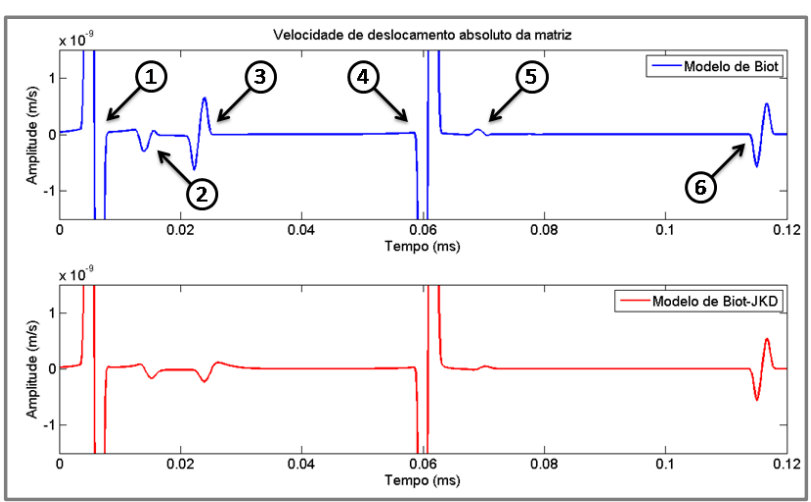

Figura 11: Zoom da velocidade de deslocamento absoluto da fase sólida para o caso simulado de altas frequências 


\section{Discussão e Conclusões}

Através da análise de dispersão e atenuação das ondas que se propagam em um meio poroelástico 1D (Figuras 1-4) verificou-se que para baixas frequências e para frequências bastante superiores à frequência crítica, quanto mais denso o fluido, menor é a velocidade de fase da onda rápida. Além disso, quanto mais viscoso o fluido, maior é a atenuação da onda lenta, tanto para o modelo de Biot, quanto para o modelo de Biot-JKD e para baixas frequências, quanto mais viscoso o fluido, menor é a atenuação da onda rápida, já para frequências muito altas, o oposto ocorre: quanto mais viscoso o fluido, maior é a atenuação da onda rápida, para ambos os modelos.

Embasado pela teoria da poroelasticidade, buscou-se analisar os resultados das simulações. A primeira análise feita foi a confirmação de que os tempos de chegada dos eventos sísmicos, para as simulações nos dois domínios de baixas e altas frequências, estavam corretos. Para tal finalidade utilizou-se a seguinte equação:

$$
t_{m}=\frac{\Delta z}{c_{p}}
$$

onde $t_{m}$ indica 0 tempo de trânsito da onda compressional no interior da camada $m$ em análise, $\Delta z$ representa a distância percorrida pela onda no interior da camada $m$ e $c_{p}$ é a velocidade de propagação da onda na camada, seja a onda rápida ou lenta.

Em seguida, observou-se que o resultado encontrado para o domínio das altas frequências (Figuras 10 e 11), apresentava uma diferença de amplitude para os eventos sísmicos relacionados com a onda lenta entre os dois modelos utilizados, de Biot e Biot-JKD. A explicação para tal fenômeno se encontra na análise de dispersão e atenuação das ondas que se propagam através de um meio poroelástico 1D (Figuras 1-4), mais especificamente na Figura 4, onde pode-se observar que a atenuação para o modelo de Biot-JKD é maior que para o modelo de Biot, no domínio das altas frequências.

Já para o resultado da simulação no domínio das baixas frequências não se notaram diferenças de amplitude entre os modelos de Biot e Biot-JKD, o que já era esperado teoricamente, haja vista que para este domínio as curvas de dispersão são similares, como pode ser visto nas Figuras 3 e 4.

Outro fenômeno muito importante que foi observado no resultado da simulação para o domínio das altas frequências (Figuras 10 e 11) foi a conversão da onda compressional rápida-lenta e também lenta-rápida, onde a onda elástica ao se propagar no meio poroelástico converte o seu modo de propagação ao refratar ou refletir em uma interface entre dois meios poroelásticos distintos.

\section{Agradecimentos}

Ao PRH-PB 226 pelo suporte financeiro e ao Laboratório de Engenharia e Exploração de Petróleo - LENEP/UENF por fornecer todas as condições necessárias à elaboração deste trabalho.

\section{Referências}

Al-Besharah, J. M.; Salman, O. A.; Akashah, S. A. Viscosity of crude oil blends. Int. Eng. Chem. Res., n. 26, p. 2445-2449, 1987.

Azeredo, M. M. Modelagem matemática e computacional da propagação de ondas sísmicas em meios poroelásticos estratificados. Tese (Doutorado). Universidade Estadual do Norte Fluminense Darcy Ribeiro, Maio 2013.

Biot, M. A. Theory of propagation of elastic waves in a fluid-saturated porous solid. i. low-frequency range. The Journal of the Acoustical Society of America, v. 28, n. 2, p. 168-178, March 1956a.

Biot, M. A. Theory of propagation of elastic waves in a fluid-saturated porous solid. ii. higher frequency range. The Journal of the Acoustical Society of America, v. 28, n. 2,p. 179-191, March 1956b.

Blanc, E. Time-domain numerical modeling of poroelastic waves: the Biot-JKD model with fractional derivatives. Tese (doutorado). AIX-Marseille Université, December 2013.

Bouzidi, Y. Numerical models of converted slow p-wave modes in porous media. In: Poromechanics $V$ ASCE. [S.I.: s.n.], 2013.

Carcione, J. M. Wave fields in real media: wave propagation in anisotropic, anelastic, porous and electromagnetic media. Second. [S.I.]: Elsevier, 2007.

Johnson, D. L.; Koplik, J.; Dashen, R. Theory of dynamic permeability and tortuosity in fluid-saturated porous media. J. Fluid Mech., v. 176, p. 379-402, 1987.

Oliveira, I. B. Modelagem de propagação das ondas elásticas em meios porosos 1D: modelos de Biot vs. BiotJKD. Dissertação (Mestrado). Universidade Estadual do Norte Fluminense Darcy Ribeiro, Fevereiro 2018.

Ursin, B. Review of elastic and eletromagnetic wave propagation in horizontally layered media. Geophysics, v. 48, n. 8, p. 1063-1081, August 1983. 